University of Nebraska - Lincoln

DigitalCommons@University of Nebraska - Lincoln

Faculty Publications, Department of Physics and Astronomy

Research Papers in Physics and Astronomy

May 2005

\title{
Epitaxial growth and magnetic properties of Cr-doped AIN thin
} films

\author{
Jun Zhang \\ University of Nebraska - Lincoln, jzhang5@unl.edu \\ Sy_Hwang Liou \\ University of Nebraska-Lincoln, sliou@unl.edu \\ David J. Sellmyer \\ University of Nebraska-Lincoln, dsellmyer@unl.edu
}

Follow this and additional works at: https://digitalcommons.unl.edu/physicsfacpub

Part of the Physics Commons

Zhang, Jun; Liou, Sy_Hwang; and Sellmyer, David J., "Epitaxial growth and magnetic properties of Crdoped AIN thin films" (2005). Faculty Publications, Department of Physics and Astronomy. 51. https://digitalcommons.unl.edu/physicsfacpub/51

This Article is brought to you for free and open access by the Research Papers in Physics and Astronomy at DigitalCommons@University of Nebraska - Lincoln. It has been accepted for inclusion in Faculty Publications, Department of Physics and Astronomy by an authorized administrator of DigitalCommons@University of Nebraska Lincoln. 


\title{
Epitaxial growth and magnetic properties of Cr-doped AlN thin films
}

\author{
Jun Zhang, Sy-Hwang Liou, and David J. Sellmyer \\ Department of Physics and Astronomy \\ Center for Materials Research and Analysis \\ University of Nebraska-Lincoln \\ Lincoln, NE 68588 \\ Submitted February 2005; revised April 2005; published 13 May 2005
}

\begin{abstract}
Cr-doped AlN thin films were epitaxially grown on $\mathrm{Al}_{2} \mathrm{O}_{3}(001)$ substrates at lowtemperature by reactivemagnetron sputtering,and their magnetic properties were investigated. Extensive $\mathrm{x}$-ray diffraction studies indicated that the films have a wurtzite-type hexagonal structure and are (001) oriented, with an epitaxial relationship of the [100] direction of the films along the [110] direction of $\mathrm{Al}_{2} \mathrm{O}_{3}$. The $c$ axis lattice parameter of the films showed a linear dependence on the $\mathrm{Cr}$ concentration for $\mathrm{Cr}$ concentrations below 0.15 . Room temperature ferromagnetism was observed, and the magnetic properties showed strong dependence on the $\mathrm{Cr}$ concentration over a wide range.
\end{abstract}

Ferromagnetic semiconductors are attracting increasing interest due to their potential applications in spintronic devices. Ferromagnetic semiconductors with Curie temperatures well above room temperature are of special interest from the viewpoints of both fundamental research and practical applications. Following theoretical predictions [1], high temperature ferromagnetism has recently been reported in doped oxides and nitrides, such as $\mathrm{ZnO}$ [2], $\mathrm{TiO}_{2}$ [3], $\mathrm{SnO}_{2}$ [4], GaN [5], and AlN [6].

AlN is one of the most promising materials for optoelectronic devices, and the realization of high temperature ferromagnetism in AlN-based materials makes it attractive for multifunctional devices. It has been reported that $\mathrm{Cr}-, \mathrm{Co}-$, and $\mathrm{Mn}$-doped $\mathrm{AlN}$ are ferromagnetic at temperatures above 300K [6-12]. So far, Cr-doped AlN films have been grown on $\mathrm{Si}$, sapphire, and $\mathrm{SiC}$ substrates by magnetron sputtering [6, 7], MBE [8, 9, 12], or ion implantation [10]. Notably, the solubility of $\mathrm{Cr}$ in AlN is much higher than that of Mn, especially in films grown at low temperatures [8]. The $\mathrm{Cr}$ concentration in $\mathrm{Cr}$-doped AlN has been reported as high as $30 \%$ [6], which is much higher than that of $\mathrm{Mn}$ in the well-studied GaMnAs [13], and low substrate temperatures could favour the incorporation of $\mathrm{Cr}$ into AlN[8]. The high solubility of transition metals in semiconductor matrices could facilitate modulating the magnetic properties of these materials. However, there has been no systematic study of the structure and magnetic properties of $\mathrm{Cr}$-doped $\mathrm{AlN}$ thin films with varying $\mathrm{Cr}$ concentrations over a wide range. In this paper, we report epitaxial growth of Cr-doped AlN thin films on sapphire substrate at low temperature by reactive magnetron sputtering, and the evolution of structure and magnetic properties with $\mathrm{Cr}$ concentration changing over a wide range from 0 to $20 \%$. 
Cr-doped AlN thin films, $\mathrm{Al}_{1-x} \mathrm{Cr}_{x} \mathrm{~N}$ (denoted as Cr-AlN), with $x$ varying from 0 to 0.20 , were grown on $\mathrm{Al}_{2} \mathrm{O}_{3}(001)$ substrates by reactive magnetron sputtering. The base pressure of the sputtering chamber is $2 \times 10^{-7}$ Torr. During sputtering the pressure of the nitrogen and argon mixture atmosphere was maintained at 0.01 Torr, and the substrate temperature was kept at $400^{\circ} \mathrm{C}$. The films are about $100 \mathrm{~nm}$ thick. Energy dispersive x-ray spectroscopy (EDS) was used to measure the Cr concentrations. Because the sampling depth of EDS $(0.1-2 \mu \mathrm{m})$ is greater than the film thickness, the $\mathrm{Al}$ signal from the $\mathrm{Al}_{2} \mathrm{O}_{3}$ substrate would be included in direct measurements of the $\mathrm{Cr} / \mathrm{Al}$ ratios of the films grown on $\mathrm{Al}_{2} \mathrm{O}_{3}$ substrate. Therefore, $\mathrm{Si}$ substrates were also loaded in the sputtering chamber to simultaneously prepare reference samples. The $\mathrm{Cr}$ concentrations of the Cr-AIN films on Si substrates were measured, and we assumed that the Cr-AlN films simultaneously grown on $\mathrm{Al}_{2} \mathrm{O}_{3}$ substrates had the same or similar $\mathrm{Cr}$ concentrations.

Various $\mathrm{x}$-ray diffraction (XRD) techniques were used to study the structural properties of the films. $\theta-2 \theta$ diffraction patterns showed that all $\mathrm{Cr}$-AlN films are of single phase with wurtzite structure and $c$ axis oriented. A typical $\theta-2 \theta$ diffraction pattern of a Cr-AlN thin film with $x=0.10$ is shown in figure 1(a) (top). Besides the diffraction peaks from the $\mathrm{Al}_{2} \mathrm{O}_{3}$ substrate (see the bottom figure of figure 1(a)), only (002) and (004) peaks from a wurtzite-type AlN hexagonal structure appeared. Figure 1(b) plots the $c$ axis lattice parameter, $c$, as a function of the Cr concentration $x$. As $x$ changes from 0 to $0.15, c$ increases almost linearly, obeying Vegard's law. This is consistent with the fact that the ion radius of $\mathrm{Cr}$ is larger than that of $\mathrm{Al}$, and suggests that $\mathrm{Cr}$ does indeed enter into the lattice of AlN and occupy the $\mathrm{Al}$ site. The linear dependence of $c$ on the $\mathrm{Cr}$ concentration does not persist as $x$ increases beyond 0.15 , probably indicating a solubility limit of $\mathrm{Cr}$ in AlN around $15 \%$, although no detectable second phase has been observed in the sample with $x=0.20$ according to XRD. The high solubility of $\mathrm{Cr}$ in AlN obtained here is almost twice that of $\mathrm{Mn}$ in GaAs. Compared with $\mathrm{Mn}$, $\mathrm{Cr}$ also has higher solubility in AIN [8]. It has been found that the incorporation of transition metal dopants in AIN decreases as the substrate temperature increases [8]. The low film growth temperature used in this work is believed to be favourable for the incorporation of $\mathrm{Cr}$ into AlN.

The structural features of Cr-AlN films were further studied by means of XRD using the phi scan and pole figure modes. A typical (100) phi scan of Cr-AlN thin films (figure 2(a)) shows six diffraction peaks with $60^{\circ}$ spacing in between, confirming the sixfold symmetry of the hexagonal structure. The sixfold hexagonal symmetry was also confirmed by the (102) pole figure shown in figure 2(b). These XRD results clearly demonstrated that high quality Cr-AlN films were epitaxially grown on the $\mathrm{Al}_{2} \mathrm{O}_{3}(001)$ substrates. The phi scans of the CrAlN film (100) and the $\mathrm{Al}_{2} \mathrm{O}_{3}$ substrate (110) (not shown here) indicate that the [100] direction of Cr-AlN is aligned with the [110] direction of the $\mathrm{Al}_{2} \mathrm{O}_{3}$ substrate, consistent with a previous report [14]. The unit cell of Cr-AlN rotates by $30^{\circ}$ along the $c$ axis compared with that of $\mathrm{Al}_{2} \mathrm{O}_{3}$, with [100] of $\mathrm{Cr}$-AlN parallel to [110] of $\mathrm{Al}_{2} \mathrm{O}_{3}$. The lattice mismatch between the [100] direction of AlN and the [110] direction of $\mathrm{Al}_{2} \mathrm{O}_{3}$ is $13.29 \%$. To explain the epitaxial growth, Sun et al [14] proposed a crystallographic model of the epitaxial relationship between AlN films and $\mathrm{Al}_{2} \mathrm{O}_{3}$ substrate, in which an extended atomic distance mismatch is just $0.70 \%$ between eight times the $\mathrm{Al}-\mathrm{Al}$ atomic distance of $\mathrm{AlN}$ and nine times the $\mathrm{Al}-\mathrm{Al}$ distance of $\mathrm{Al}_{2} \mathrm{O}_{3}$.

Magnetic properties of $\mathrm{Cr}$-AlN films were measured with a superconducting quantum interference device (SQUID) magnetometer. The diamagnetic contributions from the $\mathrm{Al}_{2} \mathrm{O}_{3}$ substrate to the total magnetization were subtracted. Room temperature ferromagnetism has been observed in all Cr-AlN films. Figure 3 shows the magnetization versus magnetic field curves for the Cr-AlN $(x=0.05)$ films at 5 and $300 \mathrm{~K}$. Well-defined open hysteresis loops were observed at both temperatures, with considerable coercive field and remanence. At 5 
$\mathrm{K}$, the coercive field is about $355 \mathrm{Oe}$, and the saturation moment is about $0.08 \mu_{\mathrm{B}} / \mathrm{Cr}$. Both the saturation magnetization and the coercive field decreased as temperature increased to 300 $\mathrm{K}$. The weak temperature dependence of the magnetization below $300 \mathrm{~K}$ is quite consistent with the previous report [7], and suggests that the Curie temperature is well above $300 \mathrm{~K} . T_{\mathrm{C}}$ above $900 \mathrm{~K}$ has been reported [7, 9].

The $\mathrm{Cr}$ concentration dependence of the magnetic properties was investigated. As shown in figure 4, as the $\mathrm{Cr}$ concentration increases, both the effective magnetic moment per $\mathrm{Cr}$ atom $\left(\mu_{\mathrm{Cr}}\right)$ and the coercive field $\left(H_{\mathrm{C}}\right)$ measured at $300 \mathrm{~K}$ gradually decrease. Similar dependences of magnetic properties on the magnetic dopant concentration have been observed
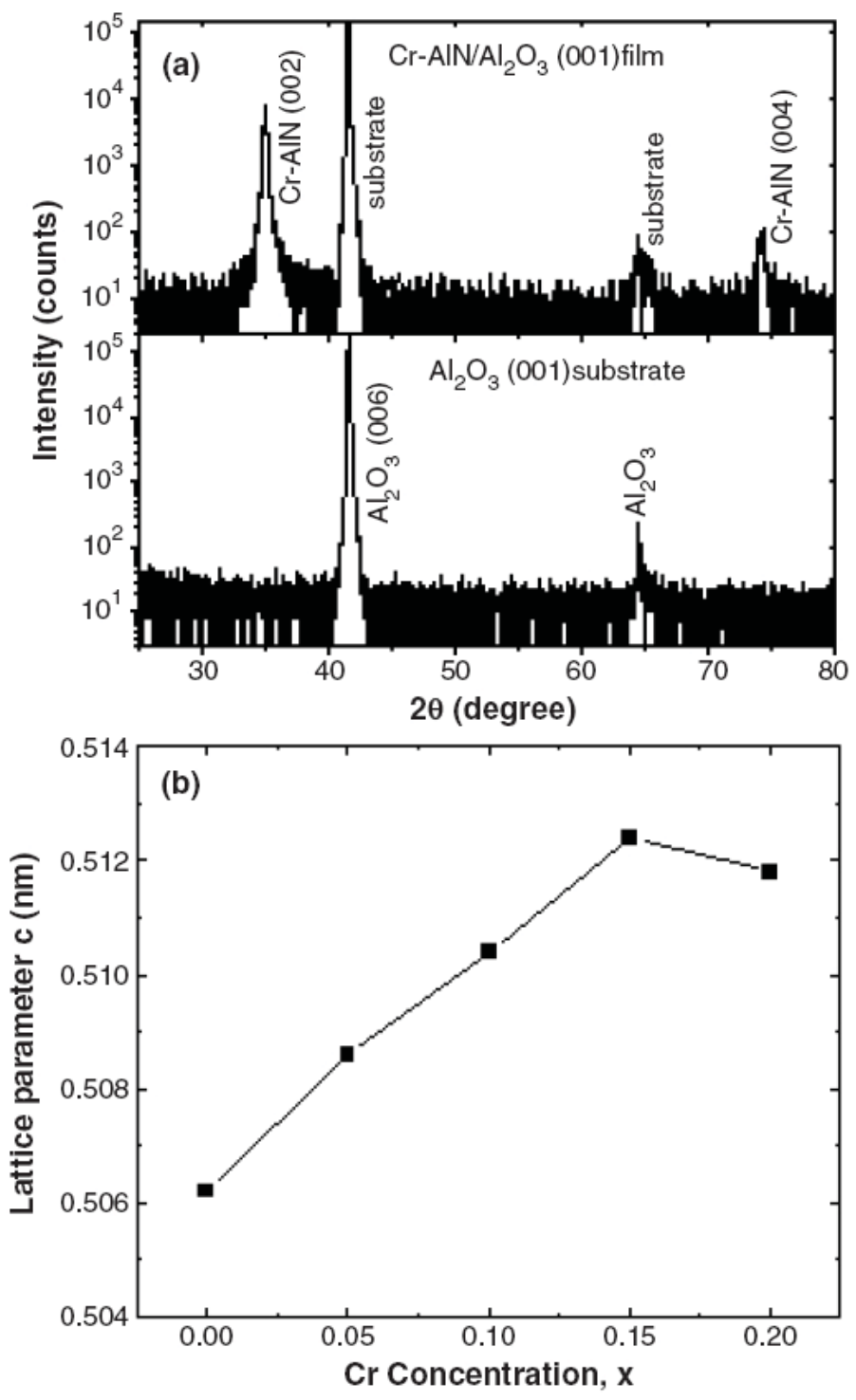

Figure 1. (a) X-ray diffraction patterns $\left(\theta-2 \theta\right.$ scan) of a $\mathrm{Cr}-\mathrm{AlN}(x=0.10)$ film on $\mathrm{Al}_{2} \mathrm{O}_{3}(001)$ substrate (top) and an $\mathrm{Al}_{2} \mathrm{O}_{3}(001)$ substrate (bottom). In the Cr-AlN film, the peak around $65^{\circ}$ is from the $\mathrm{Al}_{2} \mathrm{O}_{3}$ substrate, because it also appears in the XRD pattern of the $\mathrm{Al}_{2} \mathrm{O}_{3}(001)$ substrate. (b) $c$ axis lattice parameter $c$ of Cr-AlN film as a function of $\mathrm{Cr}$ concentration. 
in other magnetic semiconductor systems, such as Mn-doped GaAs [13], Mn-doped GaN [15], and Co-doped $\mathrm{SnO}_{2}$ [4]. In [15], Mn-doped $\mathrm{GaN}$ showed lower magnetic moment at higher Mn content, which was attributed to the presence of increasing interstitial Mn due to a low Mn solubility limit of only 3\%. In the Cr-AlN films reported here, the solubility of $\mathrm{Cr}$ is much higher $(\sim 15 \%)$. Although the possibility of the existence of interstitial $\mathrm{Cr}$ for $x<0.15$ cannot be excluded, the $\mathrm{Cr}$ concentration dependence of the lattice parameter suggests that for $x<0.15$, Cr mainly goes into substitutional sites, and for $x>0.15$, Cr may mainly go into other sites. Therefore, we speculate that for $x<0.15$, the amount of interstitial $\mathrm{Cr}$ (if any exists) is not expected to increase significantly as $x$ increases, and the reduced magnetic moment at higher $\mathrm{Cr}$ concentrations may be mainly attributed to enhanced antiferromagnetic coupling between neighbouring substitutional $\mathrm{Cr}$ ions [7]; however, as $x>0.15$, the amount of interstitial $\mathrm{Cr}$ may increase significantly, which further reduces the average moment. The low magnetic moment suggests that only a very small fraction of $\mathrm{Cr}$ contributes to the ferromagnetic ordering. The magnetic moments in our samples are in good agreement with the results observed by Kumar et al [7] for their Cr-AlN thin films grown by reactive sputtering at conditions similar to ours, but lower than those obtained for the films grown by the molecular beam epitaxy method $[8,9]$. Film growth conditions (e.g., base pressure and growth pressure) may affect the defect states in the films and hence, as discussed below, their magnetic properties.
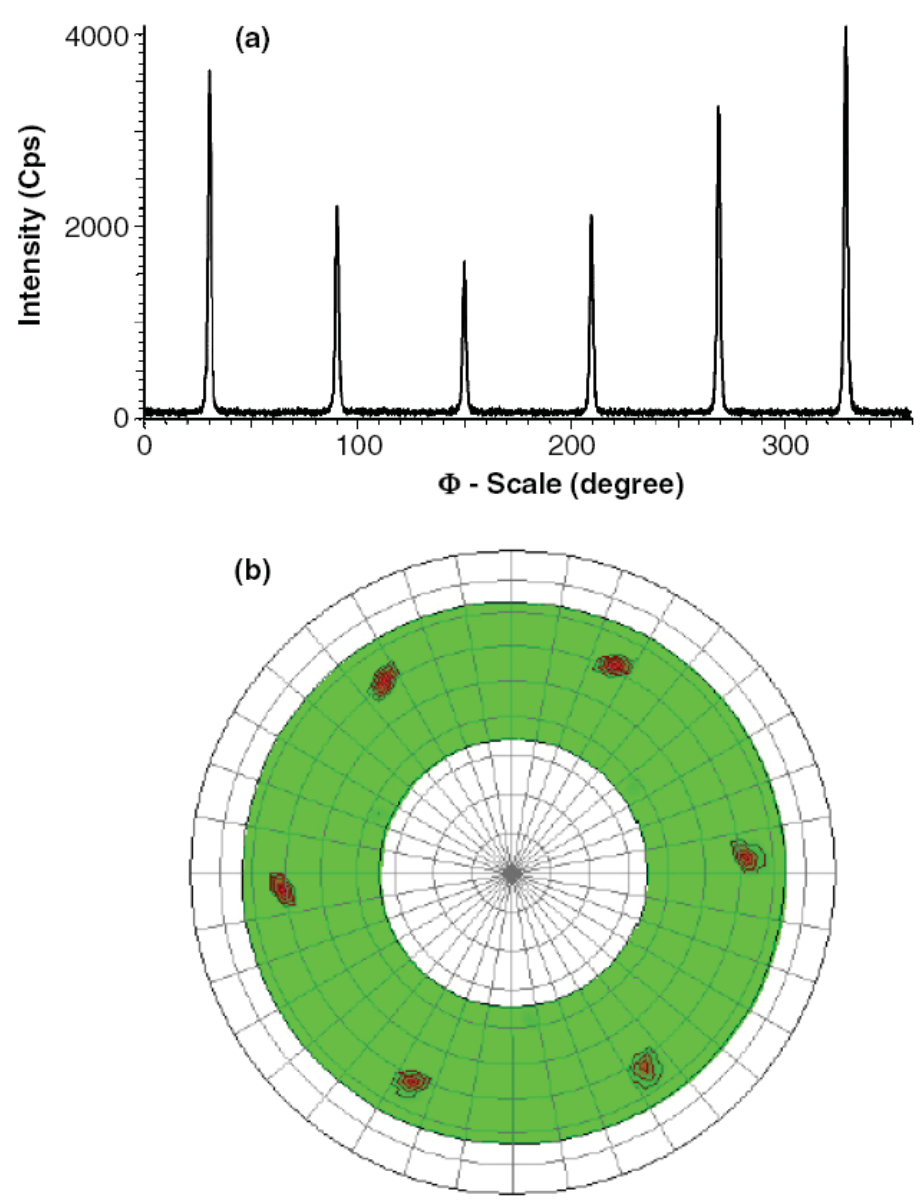

Figure 2. X-ray diffraction (100) phi scan (a) and (102) pole figure (b) of a Cr-AlN ( $x=0.10)$ film. 
The carrier-mediated ferromagnetism [1] that is well accepted for Mn-doped GaAs does not seem to be applicable in nitride $[9,10,16]$ and oxide [17] systems. A double-exchange mechanism was suggested for the ferromagnetism in nitrides such as Cr-AlN [9]. Recently, Kaminski and Das Sarma [18] and Coey and co-workers [17, 19, 20] have proposed bound magnetic polaron models for ferromagnetism in poorly conducting semiconductors. Ferromagnetic exchange in dilute ferromagnetic oxides and nitrides is suggested to be mediated by localized electrons that form bound magnetic polarons, which overlap to create a spinsplit impurity band. Ferromagnetism is predicted to happen at the polaron percolation threshold. The bound magnetic polarons consist of electrons surrounding defects, such as oxygen

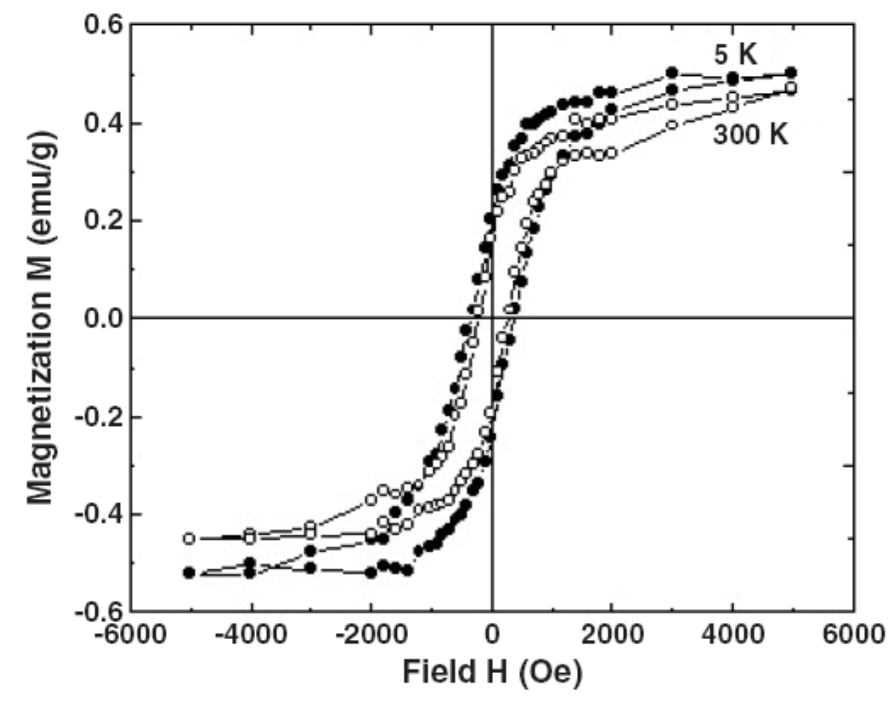

Figure 3. Hysteresis loops of one Cr-AlN film $(x=0.05)$ measured at 5 and $300 \mathrm{~K}$.

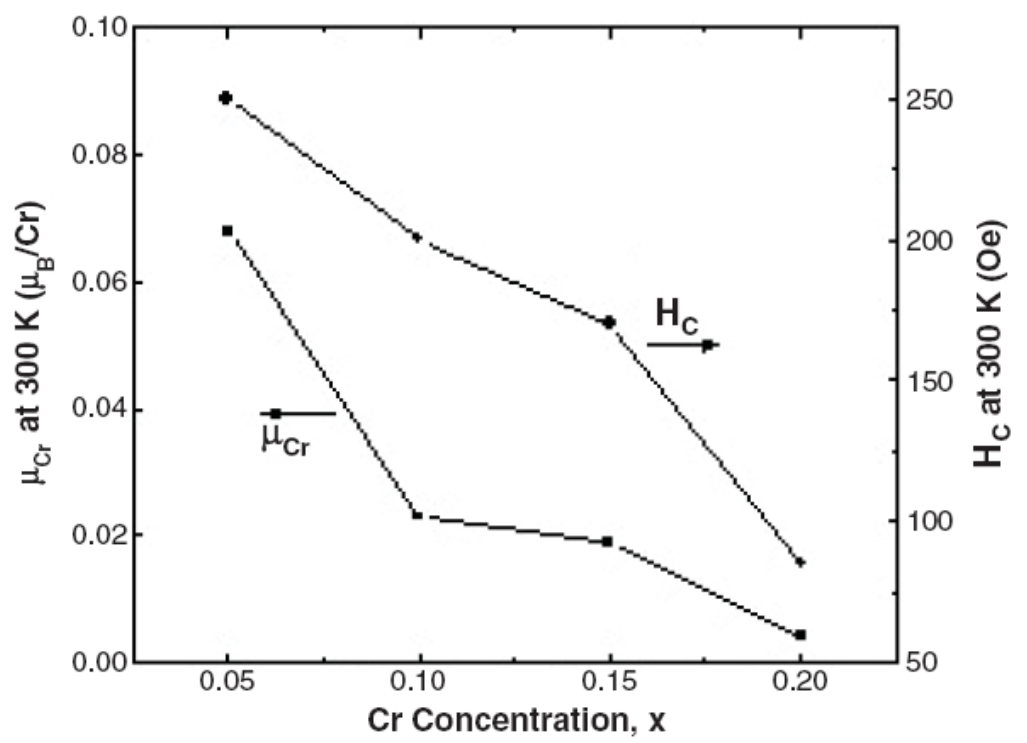

Figure 4. Cr concentration dependence of the effective magnetic moment $\left(\mu_{\mathrm{Cr}}\right)$ and coercive field $\left(H_{\mathrm{C}}\right)$ at $300 \mathrm{~K}$ for the Cr-AlN films. 
or nitrogen vacancies, and the Bohr orbital radius of the polaron is $\gamma \alpha_{0}\left(\alpha_{0}\right.$ is the Bohr radius and $\gamma$ is defined as $\varepsilon m_{\mathrm{e}} / m^{*}$, where $\varepsilon$ is the high frequency dielectric constant, $m_{\mathrm{e}}$ is the electron mass, and $m^{*}$ is the electron effective mass) $[19,20]$. In the case of Cr-AlN, the Bohr orbital radius of polarons would be about $8.5 \AA$. Obviously, defects such as anion vacancies have important roles in the formation of the magnetic polarons, and hence the ferromagnetism. Taking this model into account may help us to understand the different magnetic moments obtained in the Cr-AlN films grown at different conditions as mentioned above.

In summary,we have grown ferromagnetic Cr-doped AlN films epitaxially on $\mathrm{Al}_{2} \mathrm{O}_{3}(001)$ substrates at low temperature. The films were of wurtzite-type hexagonal structure and $c$ axis oriented with the [100] direction along the [110] direction of $\mathrm{Al}_{2} \mathrm{O}_{3}$. The solubility limit of $\mathrm{Cr}$ in $\mathrm{AlN}$ is around $15 \%$. Room temperature ferromagnetism was observed in the films, and the magnetic properties showed strong dependence on the $\mathrm{Cr}$ concentration in a wide range.

\section{Acknowledgments}

We would like to thank Brian Jones, Bruker AXS and Rigaku, for help with XRD measurements. This research was supported by ONR, NSF-MRSEC, NRI and CMRA.

\section{References}

[1] Dietl T, Ohno H, Matsukura F, Cibert J, and Ferrand D 2000 Science 2871019

[2] Ueda K, Tabata H, and Kawai T 2001 Appl. Phys. Lett. 79988

[3] Matsumoto Y, Murakami M, Shono T, Hasegawa T, Fukumura T, Kawasaki M, Ahmet P, Chikyow T, Koshihara S, and Koinuma H 2001 Science 291854

[4] Ogale S B, Choudhary R J, Buban J P, Lofland S E, Shinde S R, Kale S N, Kulkarni V N, Higgins J, Lanci C, Simpson J R, Browning N D, Das S S, Drew H D, Greene R L, and Venkatesan T 2003 Phys. Rev. Lett. 91077205

[5] Reed M L, El-Masry N A, Stadelmaier H H, Ritums M K, Reed M J, Parker C A, Roberts J C, and Bedair S M 2001 Appl. Phys. Lett. 793473

[6] Yang S G, Pakhomov A B, Hung S T, and Wong C Y 2002 Appl. Phys. Lett. 812418

[7] Kumar D, Antifakos J, Blamire M G, and Barber Z H 2004 Appl. Phys. Lett. 845004

[8] Wu S Y, Liu H X, Gu L, Singh R K, Budd L, Schilfgaarde M, MaCartney M R, Smith D J, and Newman N 2003 Appl. Phys. Lett. 823047

[9] Liu H X, Wu S Y, Singh R K, Gu L, Smith D J, Newman N, Dilley N R, Montes L, and Simmonds M B 2004 Appl. Phys. Lett. 854076

[10] Frazier R, Stapleton J, Thaler G, Abernathy C R, Pearton S J, Rairigh R, Kelly J, Hebard A F, Nakarmi M L, Nam K B, Lin J Y, Jiang H X, Zavada J M, and Wilson R G 2003 J. Appl. Phys. 941592

[11] Frazier R, Thaler G, Overberg M, Gila B, Abernathy C R, and Pearton S J 2003 Appl. Phys. Lett. 83 1758

[12] Frazier R, Thaler G, Leifer J, Hite J, Gila B, Abernathy C R, and Pearton S J 2005 Appl. Phys. Lett. 86 052101

[13] Potashnik S J, Ku K C,Wang R F, Stone M B, Samarth N, Schiffer S, and Chun S H 2003 J. Appl. Phys. 936784

[14] Sun C J, Kung P, Saxler A, Ohsato H, Haritos K, and Razeghi M 1994 J. Appl. Phys. 753964

[15] Thaler G, Frazier R, Gila B, Stapleton J, Davidson M, Abernathy C R, Pearton S J, and Segre C 2004 Appl. Phys. Lett. 841314

[16] Graf T, Gjukic M, Brandt M S, Stutzmann M, and Ambacher O 2002 Appl. Phys. Lett. 815159

[17] Coey J M D, Douvalis A P, Fitzgerald C B, and Venkatesan M 2004 Appl. Phys. Lett. 841332

[18] Kaminski A and Das S S 2002 Phys. Rev. Lett. 88247202

[19] Venkatesan M, Fitzgerald C B, Lunney J G, and Coey J M D 2004 Phys. Rev. Lett. 93177206

[20] Coey J M D, Venkatesan M, and Fitzgerald C B 2005 Nat. Mater. 4173 